\title{
Effects of climate warming and declining species richness in grassland model ecosystems: acclimation of $\mathrm{CO}_{2}$ fluxes
}

\author{
S. Vicca ${ }^{1}$, P. Serrano-Ortiz ${ }^{2}$, H. J. De Boeck ${ }^{1}$, C. M. H. M. Lemmens ${ }^{1}$, I. Nijs ${ }^{1}$, R. Ceulemans ${ }^{1}$, A. S. Kowalski ${ }^{2}$, and \\ I. A. Janssens ${ }^{1}$ \\ ${ }^{1}$ Research Group of Plant and Vegetation Ecology, Department of Biology, University of Antwerp (Campus Drie Eiken), \\ Universiteitsplein 1, 2610 Wilrijk, Belgium \\ ${ }^{2}$ Department of Applied Physics, University of Granada, C/ Fuentenueva S/N, 18071 Granada, Spain
}

Received: 28 August 2006 - Published in Biogeosciences Discuss.: 22 September 2006

Revised: 6 December 2006 - Accepted: 19 December 2006 - Published: 12 January 2007

\begin{abstract}
To study the effects of warming and declining species richness on the carbon balance of grassland communities, model ecosystems containing one, three or nine species were exposed to ambient and elevated (ambient $+3^{\circ} \mathrm{C}$ ) air temperature. In this paper, we analyze measured ecosystem $\mathrm{CO}_{2}$ fluxes to test whether ecosystem photosynthesis and respiration had acclimated to warming after 28 months of continuous heating, and whether the degree of acclimation depended on species richness. In order to test whether acclimation occurred, short term temperature response curves were established for all communities in both treatments. At similar temperatures, lower flux rates in the heated communities as compared to the unheated communities would indicate thermal acclimation. Because plant cover was significantly higher in the heated treatment, we normalized the data for plant cover. Subsequently, down-regulation of both photosynthesis and respiration was observed. Although $\mathrm{CO}_{2}$ fluxes were larger in communities with higher species richness, species richness did not affect the degree of acclimation to warming. These results imply that models need to take thermal acclimation into account to simulate photosynthesis and respiration in a warmer world.
\end{abstract}

\section{Introduction}

Both photosynthesis and respiration are known to increase with temperature, albeit not necessarily to the same degree, until an optimum temperature is reached (Saxe et al., 2001; Larcher, 2003). Because rising global temperatures could influence the global carbon balance, it is important to study to what extent future climate will affect the carbon balance of terrestrial ecosystems.

Correspondence to: S. Vicca

(sara.vicca@ua.ac.be)
Although photosynthetic and respiratory rates increase with temperature (Larcher, 2003), both processes and their resulting $\mathrm{CO}_{2}$ fluxes may also acclimate to warming conditions (Rook, 1969; Körner and Larcher, 1988; Bryla et al., 1997, 2001; Atkin et al., 2000a, 2006; Atkin and Tjoelker, 2003; King et al., 2006). Acclimation can be defined as the adjustment of processes such that plant performance is adapted to the new growth temperature (Lambers et al., 1998). Acclimation could mitigate, offset, or even enhance the predicted increases in photosynthesis and respiration. According to Atkin and Tjoelker (2003), acclimation of respiration can be associated with temperature-mediated changes in respiratory capacity, availability of substrates, and/or the demand for respiratory energy. Heterotrophic respiration $\left(R_{h}\right)$ is reported to acclimate to higher temperatures as well (Luo et al., 2001), which is most likely due to depletion of labile soil organic carbon pools (Melillo et al., 2002; Kirschbaum, 2004; Eliasson et al., 2005). Acclimation of photosynthesis, on the other hand, might be due to inactivation of Rubisco and/or leakiness of photosynthetic membranes (Sharkey, 2005). Photosynthetic acclimation also can result from either a shift in optimum temperature or an adjustment of photosynthetic rates at all temperatures (Berry and Björkman, 1980; Saxe et al., 2001).

Global change comprises several factors beyond climate warming, among which the loss of biodiversity is key. The functional importance of biodiversity is reported in numerous studies, describing for example reductions in biomass resulting from declining species richness (e.g. Hector et al., 1999; Van Ruijven and Berendse, 2005). Three mechanisms might explain how diversity influences productivity in plant communities: (a) complementarity, (b) facilitation, and (c) the sampling effect (Fridley, 2001).

Published by Copernicus GmbH on behalf of the European Geosciences Union. 
1. Complementarity implies the variation in location, time and type of resource utilization by different species. This can result in reduced competition and more complete exploitation of resources in more species-rich communities (Fridley, 2001).

2. Vandermeer (1989) defined facilitation as the circumstance where a species modifies its environment in a way favorable to co-occuring species. Examples of facilitative mechanisms are: nitrogen enrichment by $\mathrm{N}$ fixers, water sharing via hydraulic lift (Caldwell et al., 1998), and nutrient sharing via mycorrhizal networks (Read, 1997).

3. The sampling effect can be separated into the greater likelihood of selecting a species (i) better adapted to the particular site conditions, and (ii) of higher potential growth rate or larger mature size (Fridley, 2001).

In accordance with these mechanisms, declining species richness may result in reduced plant productivity (Tillman et al., 1996; Symstad et al., 1998), and subsequently in smaller $\mathrm{CO}_{2}$ fluxes. In particular, functional group diversity is assumed to be an important factor (Sphen et al., 2000; Roy, 2001), because between-functional-group differences are larger than within-functional-group differences, and thus complementarity, facilitation and sampling effects will be more pronounced in communities with higher functional diversity (Sphen et al., 2000).

Because the effects of different global change factors are not simply additive, it is important to know to what extent factors such as climate warming and biodiversity loss may interact. However, to our knowledge, experiments investigating interactions between these two types of global change have not been performed before. In this paper we present results from a long-term warming experiment in which different species richness levels are incorporated. We hypothesize that both photosynthesis and total ecosystem respiration acclimate to elevated temperatures after long-term continuous heating. This hypothesis was tested by making short term temperature response curves for all communities in both treatments. At similar temperatures, lower flux rates in the heated communities as compared to the unheated communities would then indicate thermal acclimation. However, because photosynthesis and respiration are known to be interdependent (Hoefnagel et al., 1998), the ratio of respiration to photosynthesis is hypothesized to remain unaffected.

Last, we hypothesize that plant biomass and ecosystem $\mathrm{CO}_{2}$ fluxes are negatively influenced by loss of biodiversity. However, because acclimation is a physiological process, we do not expect species richness to have any influence on acclimation. Nonetheless, this has never been investigated. Therefore, we also tested the hypothesis that declining species richness results in reduced acclimation.

\section{Materials and methods}

\subsection{Study site}

This study was conducted at the Drie Eiken Campus of the University of Antwerp (Belgium, $51^{\circ} 09^{\prime} \mathrm{N}, 04^{\circ} 24^{\prime} \mathrm{E}$ ). The climate of northern Belgium is characterized by mild winters and cool summers, with average annual air temperatures $\left(T_{\text {air }}\right)$ varying around $9.6^{\circ} \mathrm{C}$. Annual precipitation averages $776 \mathrm{~mm}$, and is more or less equally distributed throughout the year.

In July 2003, an experimental platform containing 288 artificially assembled grassland model ecosystems was established. The platform consisted of 12 sunlit, climatecontrolled chambers, of which six were exposed to ambient $T_{\text {air }}$ (unheated chambers). The other six (heated chambers) were continuously heated $3{ }^{\circ} \mathrm{C}$ above $T_{\text {air }}$, such that temperatures in these chambers varied to the same degree as $T_{\text {air }}$. Each of these 12 chambers contained 24 different grassland communities of varying plant species richness $(S)$ : nine $S=1$ communities, nine $S=3$ communities and six $S=9$ communities. We selected species from three functional groups, which were equally represented at each $S$ level: three grass species (Dactylis glomerata L., Festuca arundinacea Schreb., Lolium perenne L.), three $\mathrm{N}$-fixing dicots (Trifolium repens L., Medicago sativa L., Lotus corniculatus L.), and three non-N-fixing dicots (Bellis perennis L., Rumex acetosa L., Plantago lanceolata L.). Species, representing the three functional groups, were used to create the $S=3$ communities, and each species combination occurred only once. The $S=9$ communities contained all nine species. For more details regarding community compositions, we refer to De Boeck et al. (2006). The position of the different communities varied between the chambers, but one unheated and one heated chamber always exhibited the same positioning. Each plant community was placed in a PVC tube with a height of $60 \mathrm{~cm}$ and an inner diameter of $24 \mathrm{~cm}$. The PVC tubes were filled with sieved loamy soil from an arable field. Soil texture and carbon content are given in Table 1 . The communities were packed closely together within the chambers, with a space of $1 \mathrm{~cm}$ between neighboring pots.

Further details regarding the experimental set-up are given by Lemmens et al. (2006).

\subsection{Measurements of carbon dioxide fluxes}

Carbon dioxide fluxes were measured in November and December 2005, 28 months after the start of the experiment, and all measurements were made between $9 \mathrm{~h} 30$ and $17 \mathrm{~h}$. First, a transparent polymethyl pentene cuvette $(60 \mathrm{~cm}$ high; $25 \mathrm{~cm}$ in diameter) was placed on the permanent soil collars. This cuvette was shaped such that it fitted the collars perfectly and air tightness was ensured by a gas tight seal. Flux measurements were performed with an infrared gas analyzer (IRGA; EGM-4; PP Systems, Hitchin, UK), which was coupled to 
Table 1. Texture and soil carbon content of the soil in the plant communities at the start of the experiment. Values in parentheses represent the standard errors.

\begin{tabular}{ll}
\hline \multicolumn{2}{c}{ Texture } \\
\hline Sand $(>53 \mu \mathrm{m}):$ & $8.7 \%(1.4)$ \\
Silt $(2-53 \mu \mathrm{m}):$ & $76.3 \%(0.9)$ \\
Clay $(<2 \mu \mathrm{m}):$ & $14.8 \%(0.4)$ \\
\hline \multicolumn{2}{c}{ Soil carbon content } \\
\hline g C/100 g soil: & $1.6(0.2)$ \\
\hline
\end{tabular}

the cuvette. During the measurements, a quantum sensor (JYP 1000, SDEC, France) inside the cuvette measured photosynthetic photon flux density $(P P F D)$. Two aerators guaranteed well-mixed air.

After placing the cuvette, net ecosystem exchange of $\mathrm{CO}_{2}$ (NEE) was measured. Subsequently, measurements of total ecosystem respiration (TER) were performed in the dark, immediately after we covered the cuvette with a black cloth, preventing photosynthesis. Gross primary productivity $(G P P)$ could then be calculated as: $G P P=N E E-T E R$. We are aware of the fact that this calculation can cause a slight (max 5-10\%) overestimate of GPP, because leaf respiration is partially inhibited in the light (Atkin et al., 2000b). However, in this study our interest primarily lies in the relative differences in GPP among temperature treatments, not in absolute values of GPP. We therefore believe that the method used was suitable for our study.

Carbon dioxide fluxes were measured in the eight central plant communities (three of $S=1$, three of $S=3$ and two of $S=9$ ) inside each of six chambers (three unheated and three heated). Inside each of the chambers air temperature and relative humidity were measured continuously with a combined QFA66 humidity-temperature sensor (Siemens, type QFA66, Germany), and 30-min means were stored.

To assess acclimation, $\mathrm{CO}_{2}$ fluxes from all plant communities were measured twice at three different air temperatures. Measurements were performed during three periods of approximately one week. One month earlier, from 24 October until 28 October, aboveground biomass was harvested at $3.5 \mathrm{~cm}$ height. As a result of this harvest, plants never spread out of the pots during our measurement periods. Two days before each measurement period, air temperatures inside the chambers were altered in order to enlarge the temperature range ( $T_{\text {air }}$ was still fluctuating in accordance with ambient temperatures). This was necessary for making regressions of TER versus temperature. Throughout this study, air temperatures ranged between 3 and $13^{\circ} \mathrm{C}$ in both temperature treatments. Furthermore, during our flux measurements, soil temperatures did not differ significantly between unheated and heated plant communities (data not shown). In Table 2 the experimental set-up of the measurements is presented.
Table 2. Experimental set-up of the measurements.

\begin{tabular}{lcc}
\hline \multirow{2}{*}{ Period } & \multicolumn{2}{c}{ Temperature Treatment } \\
\cline { 2 - 3 } & Unheated & Heated \\
\hline $1(22-25 / 11 / 2005)$ & ambient & ambient $+3^{\circ} \mathrm{C}$ \\
$2(28-30 / 11 / 2005)$ & ambient $+8^{\circ} \mathrm{C}$ & ambient $+8^{\circ} \mathrm{C}$ \\
$3(5-8 / 12 / 2005)$ & ambient $+3^{\circ} \mathrm{C}$ & ambient \\
\hline
\end{tabular}

\subsection{Water supply}

One day before each of the three measurement periods, soil water content $(S W C)$ was measured in all communities with a TRIME portable TDR soil moisture meter (MESA systems Co., USA). When $S W C$ differed between temperature treatments, we adjusted the water supply, such that variation in $S W C$ between heated and unheated communities was minimal. During the flux measurements, $S W C$ never differed significantly between temperature treatments ( $p$ values being $0.46,0.37$ and 0.59 for periods 1,2 and 3 , respectively; paired $t$-test). Consequently, observed differences in $\mathrm{CO}_{2}$ fluxes should not be due to variations in $S W C$.

\subsection{Plant cover and specific leaf area}

Ecosystem-scale $\mathrm{CO}_{2}$ effluxes include not only physiological temperature responses, but also phenological and allometrical responses. Therefore, we determined total green plant cover and specific leaf area for each of the 48 plant communities immediately after the flux measurements. Green plant cover, a measure for plant biomass, was estimated using the pin-frame method. We recorded the plant species touched by a vertical needle at each point of a 60 point matrix. Specific leaf area $(S L A)\left(\mathrm{m}^{2} \mathrm{~kg}^{-1}\right)$ of each species was also determined for each community. For this purpose, we sampled three leaves of all plant species in each of the 48 plant communities. Surface areas were measured with a Li-3000A area meter (Li-Cor, Nebraska, USA), and after being dried for $48 \mathrm{~h}$ at $70^{\circ} \mathrm{C}$, all samples were weighed. Subsequently, we calculated average SLA (average (area/mass)) for all plant species, such that differences between unheated and heated chambers could be computed.

\subsection{Data analysis}

The aim of our research was to determine whether acclimation had occurred. Because $T_{\text {air }}$ was constantly fluctuating, we wanted to compare respiration rates at a standard temperature $\left(7^{\circ} \mathrm{C}\right)$, which occurred in all plant communities. In order to estimate $T E R$ at $7^{\circ} \mathrm{C}\left(T E R_{7}\right)$, we fitted regressions for $T E R$ in Origin7 (Origin 7, Originlab, Northampton, MA, USA), using the following function:

$T E R=T E R_{7} * Q_{10}^{\left(T_{\mathrm{air}}-7\right) / 10}$ 
in which $Q_{10}$ is the temperature sensitivity of $T E R$, and $T_{\text {air }}$ (in ${ }^{\circ} \mathrm{C}$ ) is the recorded air temperature at the time of measurement. Regressions were fitted to the six measurements made for each plant community (two measurements during each of the three periods). All regressions were significant, and the uncertainty surrounding $T E R_{7}$ was on average $15 \%$. Furthermore, our raw data and fitted basal rates of respiration and $Q_{10}$ values (data not shown) did not suggest any sign of acclimation within the three day periods of our measurements. Hence, we are confident that the predicted rates at $7^{\circ} \mathrm{C}$ are correct.

Photosynthesis correlated better with light intensity than with $T_{\text {air }}\left(G P P\right.$ vs. $T_{\text {air }}$ : correlation coefficient $\rho=0.15$; $p=0.013 ; G P P$ vs. PPFD: $\rho=0.52 ; p<0.0001)$. Therefore, regressions for $G P P$ were calculated as a function of $P P F D$. Since light intensities fluctuated continuously as well, GPP $100(G P P$ at a $P P F D$ value of $100 \mu$ mol photons $\mathrm{m}^{-2} \mathrm{~s}^{-1}$ ) was estimated for each community. For this purpose, we used the following function:

$G P P=\left(Q E * P_{\max } * P P F D\right) /\left(Q E * P P F D+P_{\max }\right)$

in which $Q E$ is the quantum efficiency and $P_{\max }$ the maximum photosynthesis. In order to obtain $G P P_{100}, P P F D$ in Eq. (2) was set at $100 \mu \mathrm{mol}$ photons $\mathrm{m}^{-2} \mathrm{~s}^{-1}$. Regressions were fitted to the six measurements made in each plant community.

Since plant cover varied strongly among plant communities and between temperature treatments, it was also necessary to correct for the effect of plant cover in order to make $\mathrm{CO}_{2}$ fluxes of different communities comparable. To this end, the following function was fitted to the data, for both $T E R_{7}$ and $G P P_{100}$ :

$y=a * b^{x}$

in which $y$ is $T E R_{7}$ or $G P P_{100}$ and $x$ is the plant cover. Values $a$ and $b$ are fitted constants, determined by Origin7. Subsequently, we used the fitted functions to calculate $T E R_{7(p c 1)}$ and $G P P_{100(p c 1)}$ for the plant cover measured in each community. (To clarify: $T E R_{7(p c 1)}$ and $G P P_{100(p c 1)}$ are predicted flux rates based on the measured plant cover and Eq. (3), whereas $T E R_{7}$ and $G P P_{100}$ are measured fluxes, albeit normalized for temperature or light). Corrections for effects of plant cover were accomplished by computing residuals as $T E R_{7}-T E R_{7(p c 1)}$ and $G P P_{100}-G P P_{100(p c 1)}$ (residuals were termed $\operatorname{Resid}_{T E R}$ and $\left.\operatorname{Resid}_{G P P}\right)$. Using these residuals, unheated and heated communities with equal species composition could be compared.

In order to calculate the degree of acclimation, regressions were again fitted to $T E R_{7}$ and $G P P_{100}$ (using Eq. 3), but now this was performed for both temperature treatments separately. Subsequently, these two functions were used to calculate $T E R_{7(p c 2)}$ and $G P P_{100(p c 2)}$ for all communities, such that we could make a comparison between flux rates in the heated and unheated chambers and were able to calculate the degree of acclimation at a particular plant cover.
In summary, $T E R_{7(p c 1)}$ and $G P P_{100(p c 1)}$ are predicted fluxes, based on one fit for both temperature treatments together, and were used to calculate residuals for individual communities. These residuals could then be compared statistically to test for differences between heated and unheated communities with equal species composition. The $T E R_{7(p c 2)}$ and $G P P_{100(p c 2)}$, on the other hand, are predicted flux rates, based on separate fits for unheated and heated communities, and were computed to test for differences among temperature treatments, not communities.

\subsection{Statistics}

All statistical analyses were performed in SAS (SAS system 9.1, SAS Institute, Cary, NC, USA). To test whether $T E R_{7}$ was correlated with plant cover, a spearman-rank correlation was used, since these data were not normally distributed. For $G P P_{100}$, a Pearson correlation test could be used. Comparisons of unheated and heated communities with equal species composition were performed with a paired $t$-test. Multiple analysis of variance (MANOVA) was used to test effects of species richness and to check whether the $T E R_{7}: G P P_{100}$ ratio differed among temperature treatments. Three outliers were deleted from all analyses because the plant communities were severely disturbed. In the pair wise comparison of unheated and heated communities with equal species composition, we were obliged to delete some other communities as well, because, after two years of treatment, different species dominated in these unheated and heated communities. These plant communities could thus not be compared. As a result, comparisons of communities with equal species composition were performed for 36 communities, 18 unheated and 18 heated communities.

\section{Results}

\subsection{Phenological/allometrical responses}

Plant cover differed significantly between temperature treatments ( $p=0.02$; paired $t$-test), with an average cover of $66 \%$ in unheated communities and $81 \%$ in heated communities. This difference in cover was most pronounced in the monocultures, where plant cover was on average $33 \%$ higher in the heated communities ( $p=0.07$; paired $t$-test). For both $S=3$ and $S=9$ plant cover was only $11 \%$ and $9 \%$ higher in the heated communities and this difference was statistically not significant ( $p=0.17$ and $p=0.99$, respectively; paired $t$-test). Species richness affected plant cover as well, with lower average cover in monocultures than in $S=3$ and $S=9(p=0.05$ and $p=0.05$, respectively; MANOVA). We observed no difference between $S=3$ and $S=9$ ( $p=0.98$; MANOVA). Furthermore, no interactions were found between temperature treatment and species richness level ( $p=0.45$; MANOVA). 
Table 3. Comparison of specific leaf area $(S L A)\left(\mathrm{m}^{2} / \mathrm{kg}\right)$ in unheated $(\mathrm{U})$ and heated $(\mathrm{H})$ plant communities. Values for $\mathrm{n}$ correspond to the number of plant communities in which leaves of the respective species were sampled. Values for $S L A$ represent the average value for all plant communities in the temperature treatment and $p$ values represent the probability for a statistically significant difference between $S L A$ of species in unheated and heated communities. Bellis perennis $L$. is not shown, because it only occurred in two communities and therefore we could not carry out a statistical analysis.

\begin{tabular}{lccccc}
\hline Species & $\mathrm{n}(\mathrm{U})$ & $S L A(\mathrm{U})$ & $\mathrm{n}(\mathrm{H})$ & $S L A(\mathrm{H})$ & $p$ value \\
\hline Dactylis glomerata L. & 7 & 27.81 & 10 & 27.80 & 0.86 \\
Festuca arudinacea Schreb. & 6 & 19.97 & 7 & 19.37 & 0.85 \\
Lolium perenne L. & 3 & 19.08 & 3 & 19.70 & 0.70 \\
Lotus corniculatus L. & 2 & 24.10 & 5 & 20.18 & 0.50 \\
Medicago sativa L. & 8 & 25.76 & 9 & 25.29 & 0.67 \\
Plantago lanceolata L. & 2 & 26.60 & 7 & 22.00 & 0.12 \\
Rumex acetosa L. & 9 & 23.70 & 7 & 24.86 & 0.47 \\
Trifolium repens L. & 2 & 24.43 & 2 & 22.97 & 0.80 \\
\hline
\end{tabular}

Comparison of SLA of each species between both temperature treatments did not reveal a significant heating effect for any of the species (Table 3).

\subsection{Temperature responses of $\mathrm{CO}_{2}$ fluxes}

Neither $T E R_{7}$, nor $G P P_{100}$ was affected by heating (Fig. 1), not even when comparing unheated and heated communities with equal species composition ( $p=0.57$ and $p=0.98$, for $T E R_{7}$ and $G P P_{100}$, respectively; paired $t$-test). Similar to plant cover, both $\mathrm{CO}_{2}$ fluxes were significantly lower in monocultures than in $S=3$ and $S=9$ (TER $: p=0.02$ and $p=0.01 ; G P P_{100}: p=0.004 ; p=0.01$; each time comparing $S=1$ with $S=3$ and $S=9$, respectively; MANOVA). Again, we observed no difference between $S=3$ and $S=9$ ( $p=0.84$ and $p=0.99$, for $T E R_{7}$ and $G P P_{100}$, respectively; MANOVA). We also found no interaction between temperature treatment and $S$ level, neither for $T E R_{7}$, nor for $G P P_{100}$ ( $p=0.81$ and $p=0.94$, respectively; MANOVA).

The $T E R_{7}: G P P_{100}$ ratio did not differ between unheated and heated communities with equal species composition ( $p=0.09$; paired $t$-test; Table 4), and also species richness did not have any influence on this ratio ( $p=0.89$; MANOVA).

\section{3 $\mathrm{CO}_{2}$ fluxes normalized by plant cover}

Because $T E R_{7}$ and $G P P_{100}$ are both strongly (positively) correlated with plant cover $(\rho=0.79, p<0.0001$ and $\rho=0.80$, $p<0.0001$, respectively), it was necessary to take plant cover into account in order to verify whether physiological acclimation could have occurred. Therefore, Eq. (3) was fitted to the data to calculate $T E R_{7(p c 1)}$ and $G P P_{100(p c 1)}$ (see Materials and Methods; Fig. 2 and Table 5). Subsequently, $\operatorname{Resid}_{T E R}$ and Resid $\operatorname{RPP}_{P}$ were computed. We observed a reduction of both $\operatorname{Resid}_{T E R}$ and $\operatorname{Resid}_{G P P}$ in the heated chambers as compared to the unheated chambers ( $p=0.01$ and $p=0.01$, respectively; paired $t$-test; Fig. 3).

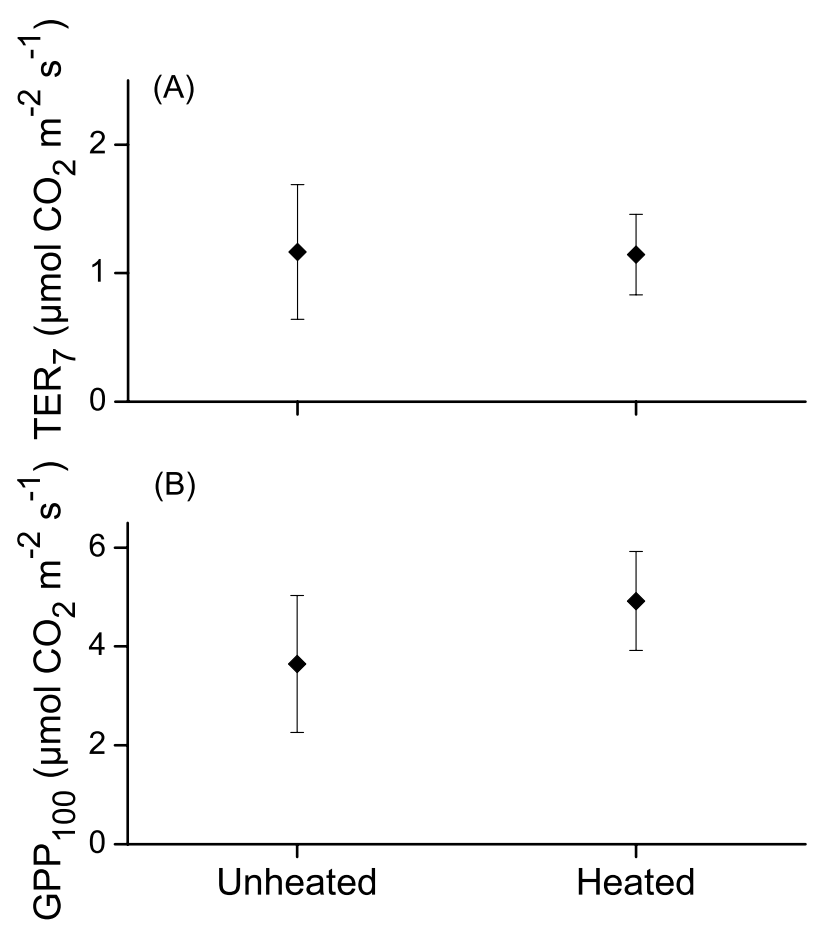

Fig. 1. (a) Total ecosystem respiration at $7^{\circ} \mathrm{C}\left(T E R_{7}\right)$ and (b) gross primary productivity at $100 \mu \mathrm{mol}$ photons $\mathrm{m}^{-2} \mathrm{~s}^{-1}\left(G P P_{100}\right)$ and their $95 \%$ confidence levels (error bars) for the two temperature treatments (unheated and heated).

This suggests that, across the entire plant cover spectrum, $T E R_{7}$ and $G P P_{100}$ were lower in the heated than in the unheated treatment. Species richness did not have any effect on $\operatorname{Resid}_{T E R}$ or Resid $\operatorname{RPP}_{\text {P }}$ ( $p=0.96$ and $p=0.92$, respectively; MANOVA), and no interactions were observed between temperature treatment and species richness level ( $p=0.50$ and $p=0.90$, for Resid $\operatorname{RER}_{T}$ and Resid $\operatorname{RPP}_{P}$, respectively; MANOVA). For this reason it was not necessary to 

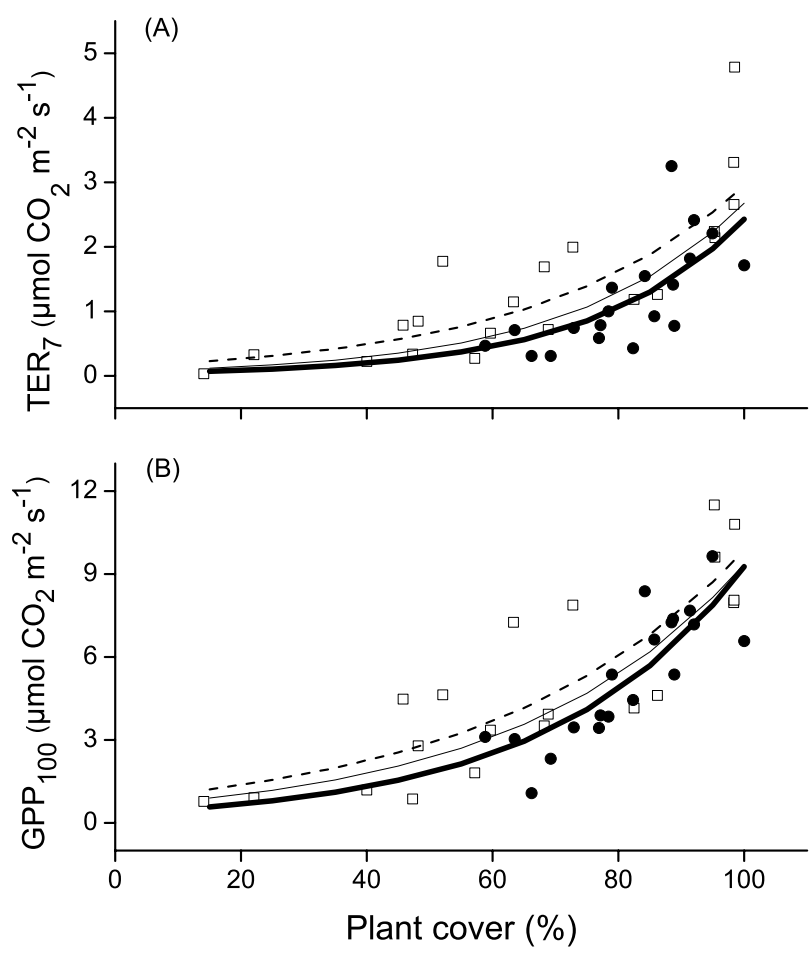

Fig. 2. (a) Total ecosystem respiration at $7^{\circ} \mathrm{C}\left(T E R_{7}\right)$ and (b) gross primary productivity at $100 \mu \mathrm{mol}$ photons $\mathrm{m}^{-2} \mathrm{~s}^{-1}\left(G P P_{100}\right)$ in function of plant cover. $\square=$ unheated communities; $\bullet=$ heated communities. Exponential regressions are given for the temperature treatments separately as well as combined. $-=$ unheated and heated communities together; $--=$ unheated communities only; - $=$ heated communities only. Parameter values and statistics for all regressions are provided in Table 5.

determine the effects of heating for each $S$ level separately, and thus, all $S$ levels could be treated together.

In order to determine the degree of acclimation, $T E R_{7(p c 2)}$ and $G P P_{100(p c 2)}$ were computed (see Materials and methods; Fig. 2 and Table 5). At a standard plant cover of 75\%, we obtained a $39 \%$ lower $T E R_{7(p c 2)}$ and a $23 \%$ lower $G P P_{100(p c 2)}$ in the heated chambers as compared to the unheated chambers. Error propagation indicated that the degrees of acclimation did not differ significantly (at $p=0.05$ ). Furthermore, when comparing the $T E R_{7}: G P P_{100}$ ratio of heated and unheated communities with equal species composition, we observed no statistical difference either ( $p=0.09$; paired $t$-test). Hence, we conclude that there was no difference in the degree of acclimation between total ecosystem respiration and photosynthesis.
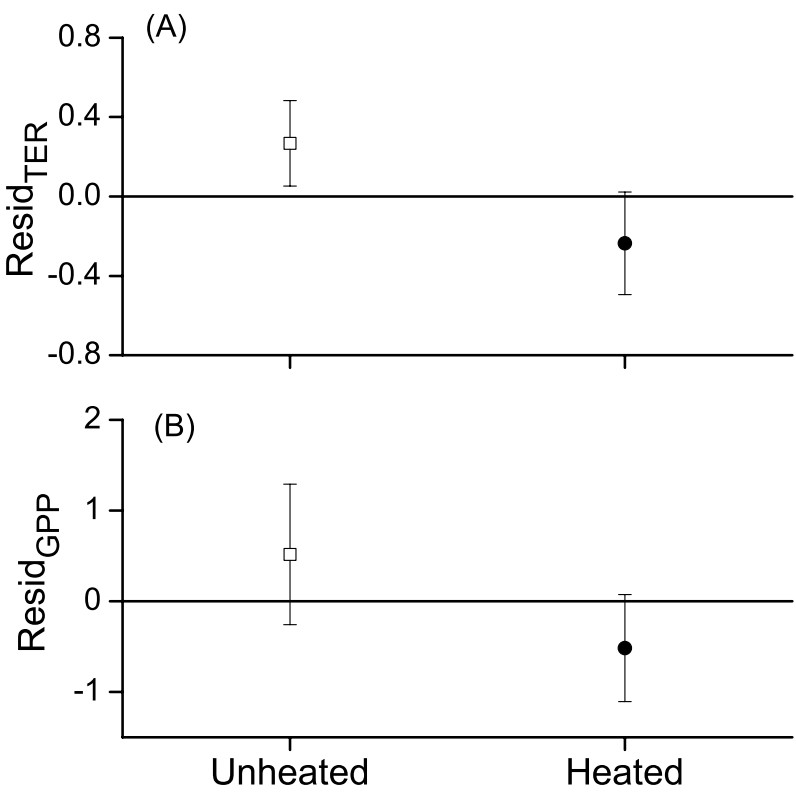

Fig. 3. Residuals between (a) measured total ecosystem respiration at $7^{\circ} \mathrm{C}\left(\mathrm{TER}_{7}\right)$ and (b) gross primary productivity at $100 \mu \mathrm{mol}$ photons $\mathrm{m}^{-2} \mathrm{~s}^{-1}($ GPP100) and the predicted values based on the observed plant cover. Error bars indicate the $95 \%$ confidence level. $\square=$ unheated communities; $\bullet=$ heated communities.

\section{Discussion}

\subsection{Heating effect}

The higher plant cover in the heated chambers points towards a phenological response to heating. We assume that the higher temperatures in the heated chambers enhanced plant and organ development, resulting in the higher plant cover observed in these communities. According to Pollock (1990), elevated temperature can indeed influence productivity.

In contrast to our results, Lemmens et al. (2006) reported a negative temperature effect on plant biomass for the same experiment at the November 2003 harvest. This reduction in biomass was, however, most likely due to enhanced soil drought in the heated chambers during summer 2003 (Lemmens et al., 2006). Furthermore, although $S W C$ was observed to be significantly lower in the heated chambers during the post-harvest time preceding our measurements (data not shown), we believe that the communities were never exposed to drought stress. Moreover, prior to our measurements, water supply was adjusted such that differences in $S W C$ were avoided during our measurements (see Materials and Methods). Therefore, because $S W C$ was sufficiently high during this current study and air temperatures were suboptimal, heated chambers likely provided better growing conditions, resulting in the higher plant cover in the heated communities. 
Table 4. Mean values and standard deviations (SD) for total ecosystem respiration at $7^{\circ} \mathrm{C}\left(T E R_{7}\right)$, gross primary productivity at $100 \mu$ mol photons $\mathrm{m}^{-2} \mathrm{~s}^{-1}\left(G P P_{100}\right)$ and the $T E R_{7}: G P P_{100}$ ratio for unheated and heated communities.

\begin{tabular}{lcccccc}
\hline \multirow{2}{*}{ Temperature treatment } & \multicolumn{2}{l}{$\mathrm{TER}_{7}\left(\mu \mathrm{mol} \mathrm{CO}_{2} \mathrm{~m}^{-2} \mathrm{~s}^{-1}\right)$} & $\mathrm{GPP}_{100}\left(\mu \mathrm{mol} \mathrm{CO}_{2} \mathrm{~m}^{-2} \mathrm{~s}^{-1}\right)$ & \multicolumn{2}{c}{$\mathrm{TER}_{7}: \mathrm{GPP}_{100}$} \\
\cline { 2 - 7 } & Mean & $\mathrm{SD}$ & Mean & $\mathrm{SD}$ & Mean & $\mathrm{SD}$ \\
\hline Unheated & 1.41 & 1.02 & 5.17 & 3.39 & 0.27 & 0.11 \\
Heated & 1.20 & 0.80 & 5.26 & 2.33 & 0.22 & 0.08 \\
\hline
\end{tabular}

Table 5. Parameter values and $\mathrm{R}^{2}$ for the fitted exponential regressions of $T E R_{7}$ (Total ecosystem respiration at $\left.7^{\circ} \mathrm{C}\right)$ and $G P P_{100}($ gross primary productivity at $100 \mu \mathrm{mol}$ photons $\left.\mathrm{m}^{-2} \mathrm{~s}^{-1}\right)$ versus plant cover (displayed in Fig. 2). The $\mathrm{R}^{2}(m$ vs. $p)$ and $p$ values $(m$ vs. $p$ ) represent the $\mathrm{R}^{2}$ and $p$ values for the linear regressions fitted for measured versus predicted fluxes. Values in parentheses represent the standard errors.

\begin{tabular}{ccccccc}
\hline & \multicolumn{2}{c}{ Unheated only } & \multicolumn{2}{c}{ Heated only } & \multicolumn{2}{c}{ Both temperature treatments combined } \\
\hline & $T E R_{7}$ & $G P P_{100}$ & $T E R_{7}$ & $G P P_{100}$ & $T E R_{7}$ & $G P P_{100}$ \\
\hline $\mathrm{a}$ & $0.146(0.058)$ & $0.838(0.287)$ & $0.037(0.034)$ & $0.355(0.159)$ & $0.068(0.033)$ & $0.592(0.173)$ \\
$\mathrm{b}$ & $1.030(0.004)$ & $1.025(0.003)$ & $1.043(0.008)$ & $1.033(0.004)$ & $1.037(0.004)$ & $1.028(0.003)$ \\
$\mathrm{R}^{2}$ & 0.771 & 0.729 & 0.481 & 0.680 & 0.592 & 0.680 \\
$\mathrm{R}^{2}(m$ vs. $p)$ & 0.212 & 0.287 & 0.564 & 0.383 & 0.339 & 0.303 \\
$\mathrm{p}$ value $(m$ vs. $p)$ & 0.041 & 0.015 & 0.0002 & 0.005 & 0.0001 & 0.0003 \\
\hline
\end{tabular}

Despite the positive heating effect on plant cover, neither $\mathrm{TER}_{7}$, nor $G P P_{100}$ differed among temperature treatments. This result points towards the occurrence of thermal acclimation. When normalized for plant cover, heated communities did indeed exhibit lower values for both $\mathrm{CO}_{2}$ fluxes than did unheated communities, which is evidence for acclimation to elevated temperatures. Thermal acclimation of $\mathrm{CO}_{2}$ fluxes was found in several other studies (Rook, 1969; Larigauderie and Körner, 1995; Loveys et al., 2003; Tjoelker et al., 1998; Atkin et al., 2006), although it did not occur in some studies on root respiration (Sowel and Spomer, 1986; Weger and Guy, 1991; Zogg et al., 1996; Burton and Pregitzer, 2003). Unfortunately, we could not partition our measured ecosystem respiratory fluxes into their autotrophic and heterotrophic components and therefore, we cannot state whether thermal acclimation of TER was due to decreased plant respiration, decreased heterotrophic respiration, or both.

The degree of acclimation appeared to differ slightly between $T E R_{7}$ and $G P P_{100}$. At $75 \%$ plant cover, we observed a higher degree of acclimation for $T E R_{7}$ than for $G P P_{100}$, which was, however, not significant. The $75 \%$ plant cover was chosen because it occurred in both temperature treatments, and because at $75 \%$ plant cover we believe to have mitigated "the compression effect". By compression effect we refer to the fact that, whereas increases in LAI are theoretically unlimited, plant cover can never exceed $100 \%$. At high values, plant cover will therefore saturate if LAI con- tinues to increase. Since respiration and photosynthesis both depend on $L A I$, it was important to restrict the use of plant cover to a range where its changes are not uncoupled from those in $L A I$.

Although $T E R_{7}$ tended to acclimate to a higher degree than $G P P_{100}$, the $T E R_{7}: G P P_{100}$ ratio did not differ among temperature treatments, indicating no difference in acclimation degrees. This latter result is considered more accurate, since the $T E R_{7}: G P P_{100}$ ratio was determined for each community separately, such that unheated and heated communities with equal species composition could be compared. Therefore, we believe that both respiration and photosynthesis exhibited equal degrees of acclimation. Moreover, degrees of acclimation are highly variable amongst species (Larigauderie and Körner, 1995; Turnbull et al., 2001; Atkin and Tjoelker, 2003, Loveys et al., 2003) and therefore comparisons should be made between communities of equal species composition. Thus, whereas the first method, computing the degree of acclimation over all plant communities, gives us an impression about the overall degree of acclimation, the second method can be considered as evidence for equal acclimation degrees for respiration and photosynthesis.

In accordance with our results, Gifford $(1994,1995)$ reported the ratio of respiration to photosynthesis in diverse species to be remarkably insensitive to growth temperature. Furthermore, he noted that the assumption that plant respiration is more temperature-dependent than photosynthesis (Ryan et al., 1996; Woodwell, 1990) is based on short-term 
experiments (Gifford, 1994). The equal $T E R_{7}: G P P_{100}$ ratio in our unheated and heated communities points towards the interdependence of respiratory and photosynthetic rates (Hoefnagel et al., 1998). This interdependence is due to the fact that respiration relies on the substrate provided by photosynthesis (Bouma et al., 1995), whereas respiration itself is crucial for the maintenance of photosynthetic activity (Krömer et al., 1995; Hoefnagel et al., 1998). Such interdependence of respiration and photosynthesis was also reported in several other experiments (e.g. Ziska and Bunce, 1998; Loveys et al., 2003; Atkin et al., 2006), and this information could be essential for determining whether global warming could alter the carbon balance of terrestrial ecosystems.

In order to determine whether the lower normalized flux rates in the heated chambers could be caused by differences in leaf morphology, we verified whether the specific leaf area differed among temperature treatments. For all species, SLA appeared to be unaffected by heating. This result is in accordance with Lemmens et al. (2006), who observed no temperature effect on SLA either, in the same set-up in September and October 2003. By contrast, Loveys et al. (2002) reported increases in $S L A$ with increasing growth temperature in 14 out of 16 species. Since we did not find a significant heating effect on SLA, we believe that in our study, acclimation was not caused by differences in specific leaf area.

\subsection{Effects of declined species richness}

The second global change factor in this experiment, declining species richness, significantly affected plant cover, with monocultures exhibiting the lowest plant cover. This is in accordance with our expectations, since complementarity and facilitation can only occur in communities with more than one species. The fact that plant cover did not differ between $S=3$ and $S=9$, which both contained three functional groups, is in agreement with the reported importance of functional group diversity (Sphen et al., 2000). In accordance, we found values for both $T E R_{7}$ and $G P P_{100}$ (not normalized for plant cover) to be lower in the monocultures than in $S=3$ and $S=9$ communities. Because the $S$ level no longer affected respiration or photosynthesis when normalized for plant cover (Resid $d_{T E R}$ and Resid ${ }_{G P P}$ were unaffected by $S$ level), the effect of species richness can be ascribed to differences in plant biomass.

As a final point, the $S$ level did not influence the $T_{E R_{7}}: G P P_{100}$ ratio, and also $\operatorname{Resid}_{T E R}$ and $\operatorname{Resid}_{G P P}$ remained unaffected. Furthermore, we observed no interactions between temperature treatment and species richness level. This implies that species richness had no effect on the normalized $\mathrm{CO}_{2}$ fluxes and therefore, we assume that species richness will not have had any influence on the degree of thermal acclimation beyond its direct effect via altered plant cover.

\section{Conclusions}

In this study, we tested the hypotheses (1) that photosynthesis and total ecosystem respiration both acclimate to elevated temperatures after long-term, continuous heating; (2) that both $\mathrm{CO}_{2}$ fluxes acclimate to the same degree; and (3) that declined species richness does not affect the degree of acclimation.

In accordance with our first hypothesis, we observed physiological acclimation of both photosynthesis and total ecosystem respiration after 28 months of continuous heating. This physiological acclimation was entirely compensated by the higher biomass in the heated chambers. Hence, at equal air temperatures, both temperature treatments exhibited similar ecosystem-scale $\mathrm{CO}_{2}$ fluxes. Moreover, our second hypothesis could not be falsified either, since heating had no effect on the ratio of respiration to photosynthesis, and degrees of acclimation are thus considered equal for both $\mathrm{CO}_{2}$ fluxes.

Declined species richness, on the other hand, resulted in reduced plant cover, and accordingly also in decreases in both $T E R_{7}$ and $G P P_{100}$. Nonetheless, neither the $T E R_{7}: G P P_{100}$ ratio, nor Resid $_{T E R}$ or $\operatorname{Resid}_{G P P}$ was affected by species richness. Thus, declined species richness did not induce or affect the observed physiological response to longterm heating, which is in accordance with our last hypothesis.

With regard to global warming, we conclude that models need to take into account the opposing effects of increasing plant cover and physiological down-regulation of photosynthesis and respiration in a warmer world.

Acknowledgements. This research was funded by the Fund for Scientific Research - Flanders (Belgium) as project "effects of biodiversity loss and climate warming on carbon sequestration mechanisms in terrestrial ecosystems", contract \#G.0434.03N. H. J. De Boeck holds a grant from the Institute for the Promotion of Innovation by science and Technology in Flanders. P. Serrano-Ortiz benefits from a pre-doctoral grant from the Junta de Andalucía. We thank F. Kockelbergh for invaluable technical assistance throughout the experiment. We are also thankful to the two anonymous referees and the editor, W. Kiessling, for their constructive comments.

Edited by: W. Kiessling

\section{References}

Atkin, O. K., Bruhn, D., Hurry, V. M., and Tjoelker, M. G.: Response of root respiration to changes in temperature and its relevance to global warming, New Phytol., 147, 141-154, 2000a.

Atkin, O. K., Evans, J. R., Ball, M. C., Lambers, H., and Pons, T. L.: Leaf respiration of snow gum in the light and the dark. Interactions between temperature and irradiance, Plant Physiol., 122, 915-923, 2000b.

Atkin, O. K., Scheurwater, I., and Pons, T. L.: High thermal acclimation potential of both photosynthesis and respiration in two 
lowland Plantago species in contrast to an alpine congeneric, Global Change Biol., 12, 500-515, 2006.

Atkin, O. K. and Tjoelker, M. G.: Thermal acclimation and the dynamic response of plant respiration to temperature, Trends in Plant Sci., 8, 343-351, 2003.

Berry, J. A. and Björkman, O.: Photosynthetic response and adaptation to temperature in higher plants, Ann. Rev. Plant Physiol., 31, 491-543, 1980.

Bouma, T. J., De Visser, R., Van Leeuwen, P. H., De Kock, M. J., and Lambers, H.: The respiratory energy requierments involved in nocturnal carbohydrate export from starch-storing mature source leaves and their contribution to leaf dark respiration, J. Exp. Bot., 46, 1185-1194, 1995.

Bryla, D. R., Bouma, T. J., and Eissenstat, D. M.: Root respiration in citrus acclimates to temperature and slows during drought, Plant Cell Environ., 20, 1411-1420, 1997.

Bryla, D. R., Bouma, T. J., Hartmond, U., and Eissenstat, D. M.: Influence of temperature and soil drying on respiration of individual roots in citrus: integrating greenhouse observations into a predictive model for the field, Plant Cell Environ., 24, 781-790, 2001.

Burton, A. and Pregitzer, K. S.: Field measurements of root respiration indicate little to no seasonal temperature acclimation for sugar maple and red pine, Tree Physiol., 23, 273-280, 2003.

Caldwell, M. M., Dawson, T. E., and Richards, J. H.: Hydraulic lift: consequences of water efflux from the roots of plants, Oecologia, 113, 151-161, 1998.

Davidson, E. A. and Janssens, I. A.: Temperature sensitivity of soil carbon decomposition and feedbacks to climate change, Nature, 440, 165-173, 2006.

De Boeck, H. J., Lemmens, C. M. H. M., Bossuyt, H., Malchair, S., Carnol, M., Merckx, R., Nijs, I., and Ceulemans, R.: How do climate warming and plant species richness affect water use in experimental grasslands?, Plant Soil, 288, 249-261, 2006.

Eliasson, P. E., McMurtrie, R. E., Pepper, D. A., Strömgren, M., Linder, S., and Agren, G. I.: The response of heterotrophic $\mathrm{CO}_{2}$ flux to soil warming, Global Change Biol., 11, 167-181, 2005.

Fridley, D.: The influence of species diversity on ecosystem productivity: how, where and why?, Oikos, 93, 514-526, 2001.

Gifford, G. M.: The global carbon cycle: A viewpoint on the missing sink, Austr. J. Plant Physiol., 21, 1-15, 1994.

Gifford, G. M.: Whole plant respiration and photosynthesis of wheat under increased $\mathrm{CO}_{2}$ concentration and temperature: long-term vs. short-term distinctions for modeling, Global Change Biol., 1, 385-396, 1995.

Hector, A., Schmid, B., Beierkuhnlein, C., Caldeira, M. C., Diemer, M., Dimitrakopoulos, P. G., Finn, J. A., Freitas, H., Gilles, P. S., Good, J., Harris, R., Högberg, P., Huss-Danell, K., Joshi, J., Jumponnen, A., Körner, C., Leadley, P. W., Loreau, M., Minns, A., Mulde, C. P. H., O’Donovan, G., Otway, S. J., Pereira, J. S., Prinz, A., Read, D. J., Scherer-Lorenzen, M., Schulze, E.-D., Siamantziouras, A.-S. D., Spehn, E. M., Terry, A. C., Troumbis, A. Y., Woodward, F. I., Yachi, S., and Lawton, J. H.: Plant diversity and productivity experiments in European grasslands, Science, 286, 1123-1127, 1999.

Hoefnagel, M. H. N., Atkin, O. K., and Wiskich, J. T.: Interdependence between chloroplasts and mitochondria in the light and the dark, Biochim. Bioph. Acta - Bioenerg., 1366, 235-255, 1998.

King, A. W., Gunderson, C. A., Post, W. M., Weston, D. J., and
Wullschleger, S. D: Plant respiration in a warmer world, Science, 312, 536-537, 2006.

Kirschbaum, M. U.: Soil respiration under prolonged soil warming: are rate reductions caused by acclimation or substrate loss?, Global Change Biol., 10, 1870-1877, 2004.

Körner, C. and Larcher, W.: Plant Life in Cold Environments, edited by: Long, S. F. and Woodward, F. I., Symposium of the Society of Experimental Biologists, The Company of Biologists Limited, Cambridge, 1988.

Krömer, S.: Respiration during photosynthesis, Ann. Rev. Plant Physiol. Mol. Biol., 46, 45-70, 1995.

Lambers, H., Chapin, F. S., and Pons, T. L.: Plant Physiological Ecology, Springer-Verlag, New York, 1998.

Larcher, W.: Physiological Plant Ecology (fourth edition), SpringerVerlag, Berlin, Heidelberg, New York, 2003.

Larigauderie, A. and Körner, C.: Acclimation of leaf dark respiration to temperature in alpine and lowland plant species, Ann. Bot., 76, 245-252, 1995.

Lemmens, C. M. H. M., De Boeck, H. J., Gielen, B., Bossuyt, H., Malchair, S., Carnol, M., Merckx, R., Nijs, I., and Ceulemans, R.: End-of-season effects of elevated temperature on ecophysiological processes of grassland species at different species richness levels, Environ. Exp. Bot., 56, 245-254, 2006.

Loveys, B. R., Atkinson, L. J., Sherlock, D. J., Roberts, R. L., Fitter, A. H., and Atkin, O. K.: Thermal acclimation of leaf and root respiration: an investigation comparing inherently fast- and slow-growing plant species, Global Change Biol., 9, 895-910, 2003.

Loveys, B. R., Scheurwater, I., Pons, T. L., Fitter, A. H., and Atkin, O. K.: Growth temperature influences the underlying components of relative growth rate: an investigation using inherently fast- and slow-growing plant species, Plant Cell Environ., 25, 975-987, 2002.

Luo, Y. Q., Wan, S. Q., Hui, D. F., and Wallace, L. L.: Acclimatization of soil respiration to warming in a tall grass prairie, Nature, 413, 622-625, 2001.

Melillo, J. M., Steudler, P. A., Aber, J. D., Newkirk, K., Lux, H., Bowles, F. P., Catricala, C., Magill, A., Ahrens, T., and Morrisseau, S.: Soil warming and carbon cycle feedbacks to the climate system, Science, 298, 2173-2175, 2002.

Pollock, C. J.: The response of plants to temperature change, J. Agricult. Sci., 115, 1-5, 1990.

Read, D.: Mycorrhizal fungi - The ties that bind, Nature, 388, $517-$ 518, 1997.

Rook, D.: The influence of growing temperature on photosynthesis and respiration of Pinus radiate seedlings, New Zealand J. Bot., 7, 43-55, 1969.

Roy, J.: Biodiversity Control of Primary Production, in: Terrestrial Global Productivity, edited by: Roy, J., Saugier, B., and Mooney, H. A., Academic Press, San Diego, USA, 169-181, 2001.

Ryan, M. G., Hunt, E. R., McMurtrie, R. E., Agren, G. I., Aber, J. D., Friend, A. D., Rastetter, E. B., Pulliam, W. M., Raison, R. J., and Linder, S.: Comparing Models of Ecosystem Function for Temperate Conifer Forests. I. Model Description and Validation, in: Global Change: Effects on Coniferous Forests and Grasslands, edited by: Breymeyer, A. I., Hall, D. O., Melillo, J. M., and Agren, G. I., SCOPE 56, Scientific Committee on Problems of the Encironment/ Wiley, Chichester, UK, 313-362, 1996.

Saxe, H., Cannell, M. G. R., Johnsen, O., Ryan, M. G., and Vourli- 
tis, G.: Tree and forest functioning in response to global warming, New Phytol., 149, 369-400, 2001.

Sharkey T.D.: Effects of moderate heat stress on photosynthesis: importance of thylakoid reactions, rubisco deactivation, reactive oxygen species, and thermotolerance provided by isoprene, Plant Cell Environ., 28, 269-277, 2005.

Sowell, J. B. and Spomer, G. G.: Ecotypic variation in root respiration rate among elevational populations of Abies lasiocarpa and Picea engelmannii, Oecologia, 68, 375-379, 1986.

Spehn, E. M., Joshi, J., Schmid, B., Diemer, M., and Körner, C.: Above-ground resource use increases with plant species richness in experimental grassland ecosystems, Funct. Ecol., 14, 326337, 2000.

Symstad, A. J., Tilman, D., Willson, J., and Knops, J. M. H.: Species loss and ecosystem functioning: effects of species identity and community composition, Oikos, 81, 389-397, 1998.

Tillman, D., Wedin, D., and Knops, J.: Productivity and sustainability influenced by biodiversity in grassland ecosystems, Nature, 379, 718-720, 1996.

Tjoelker, M. G., Oleksyn, J., and Reich, P. B.: Seedlings of five boreal tree species differ in acclimation of net photosynthesis to elevated $\mathrm{CO}_{2}$ and temperature, Tree Physiol., 18, 715-726, 1998.
Turnbull, M. H., Whitehead, D., Tissue, D. T., Schuster, W. S. F., Brown, K. J., and Griffin, K. L.: Responses of leaf respiration to temperature and leaf characteristics in three deciduous tree species vary with site water availability, Tree Physiol., 21, 571578, 2001.

Van Ruijven, J. and Berendse, F.: Diversity-productivity relationship: Initial effects, long-term patterns, and underlying mechanisms, Proc. Natl. Acad. Sci. USA, 102, 695-700, 2005

Vandermeer, J. H.: The Ecology of Intercropping, Cambridge University Press, 1989.

Weger, H. G. and Guy, R. D.: Cytochrome and alternative pathway respiration in white spruce (Picea glauca) roots. Effects of growth and measurement temperature, Physiol. Plantarum, 83, 675-681, 1991.

Woodwell, G. M.: The effects of global warming, in: Global Warming: the Greenpeace Report, edited by: Leggett, J., Oxford University Press, Oxford, UK, 116-132, 1990.

Ziska, L. H. and Bunce, J. A.: The influence of increasing growth temperature and $\mathrm{CO}_{2}$ concentration on the ratio of respiration to photosynthesis in soybean seedlings, Global Change Biol., 4, 637-643, 1998.

Zogg, G. P., Zak, D. R., Burton, A. J., and Pregitzer, K. S.: Fine root respiration in northern hardwood forests in relation to temperature and nitrogen availability, Tree Physiol., 16, 719-725, 1996. 